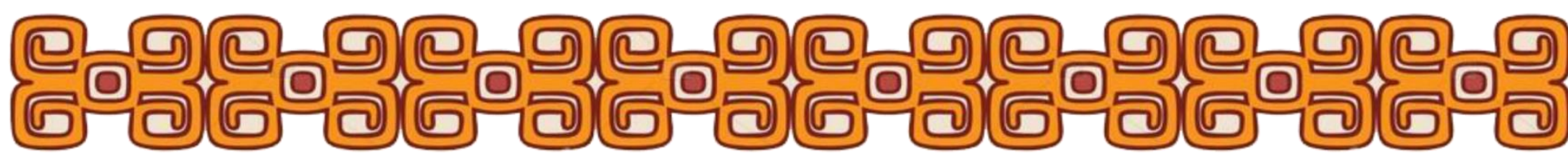

\title{
O IMAGINÁRIO GLOBAL NA PERSPECTIVA DO PENSAMENTO ECOCRÍTICO: UMA LEITURA NA POESIA DE THIAGO DE MELLO
}

\author{
Weslley Dias Cerdeira \\ Iraildes Caldas Torres
}

\section{RESUMO}

Este é um estudo do pensamento Ecocrítico voltado para as preocupações em torno da globalização. Essa é uma questão de inquietação recente por parte dos ecocríticos, sendo uma questão mal tocada que vem sendo discutida nos últimos anos. Através da perspectiva do imaginário este trabalho tem o objetivo de compreender dentro da poesia de Thiago de Mello o imaginário global. É partindo do lugar que entenderemos melhor as relações que constituem este imaginário por ter em meio às tecnologias da informação e a consciência ecológica na contemporaneidade, relações com as problemáticas globais. Essas relações, para Lawrence Buell, partem de uma dialética local-global que possibilitam o imaginar em patamares maiores que transcendem o lugar. A reflexão a partir das teorias do imaginário são fundamentais para se trazer uma compreensão cultural na constituição desse imaginário global ampliando as discussões das problemáticas ambientais.

\section{PALAVRAS-CHAVE}

Ecocrítico; Globalização; Imaginário; Lugar; Problemáticas ambientais.

\section{INTRODUÇÃO}

Este trabalho é um estudo sobre a globalização, enquanto preocupação recente dos estudos em Ecocrítica. Tal perspectiva se faz importante na contemporaneidade por esta ser, tanto dinamizadora, quanto responsável pela crise ecológica global. Durante esta discussão buscaremos tratar com bastante cautela estas preocupações em torno da globalização que ainda é tão cara aos ecocríticos, principalmente por ser um constate alvo de críticas.

Essa crítica, advinda do discurso ambientalista contemporâneo, vem implicar principalmente nos avanços do capitalismo que se estendeu com maior intensidade nos países de terceiro mundo gerando grandes impactos ambientais. O tratamento e o cuidado ao abordar a globalização na análise ecocrítica cultural ainda é uma questão pouco explorada, mas se faz importante para entender as consequências deste fenômeno e a ampliação destas discussões onde quer que elas apareçam.

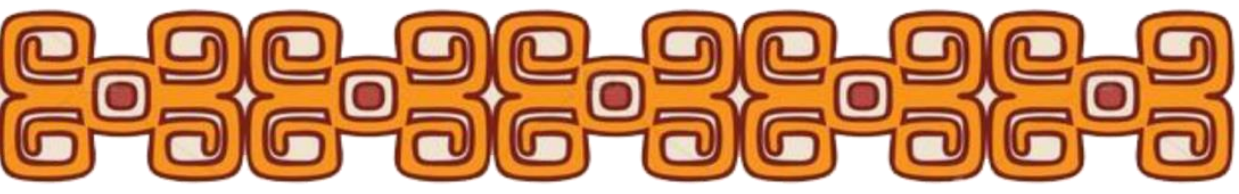




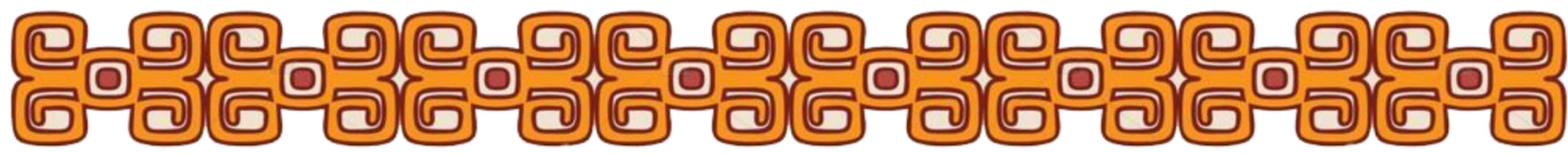

Por meio das teorias do imaginário buscaremos entender a formação desse imaginário global e a formação da consciência ecológica na contemporaneidade. Através da compreensão do imaginário será possível ter uma maior noção sobre esse contexto dentro da cultura, e mais especificamente nesta análise, dentro da literatura. Com isso, entender como a globalização influencia as manifestações culturais para com a formação de uma consciência ecológica.

Na poesia de Thiago de Mello serão avaliadas as representações que tenham um viés de conexão com a cônscia e ética ambiental. Isso mostrará muito o posicionamento do poeta no espaço cultural em que se insere, pois é a partir dele em sua maneira de ver e interpretar o seu espaço que essa análise se desenvolverá. Esse espaço é a Amazônia e buscaremos nos elementos locais de sua poesia entender as conexões com o global ampliando e esclarecendo as imagens que o poeta busca representar.

A partir das construções imagéticas do seu imaginário poético do lugar, buscaremos entender a globalização em uma relação dialética entre local-global que serão discutidas mais detalhadamente. Por isso se faz importante compreender o encontro cruzado entre a matéria poética e questões ambientais, sendo cruciais na seleção dos poemas que tematizem uma preocupação ecocrítica. É nesse encontro cruzado que sua poesia se encontra com o global e como as questões ambientais, podendo ser discutidas em outros patamares.

Fazendo a reflexão ecocrítica através do imaginário este trabalho se propõe a trazer um discurso inovador e transformador que possibilite analisar o contexto em que se formam as imagens poéticas de Thiago de Mello e como podem ser discutidas em caráter global. É papel da ecocrítica analisar estes fenômenos e abrir espaços de discussões sobre estes problemas ambientais, pois por mais que não seja seu objetivo solucionar estes problemas, deve reconhecer "a existência dos problemas, sua extensão, a natureza das ameaças e suas possíveis soluções." (Garrard, 2006, p. 16). Isso só é possível ampliando as problemáticas que podem ser entendidas em caráter global.

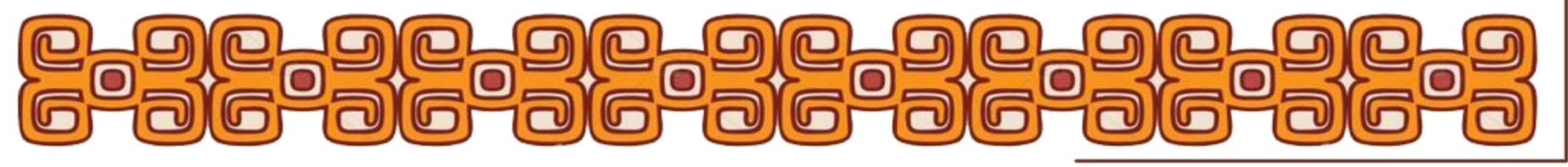




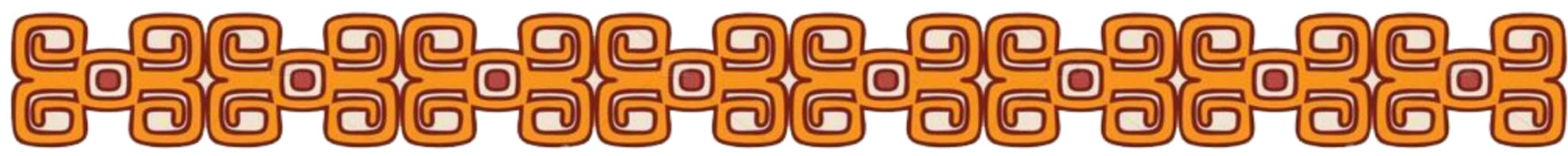

ambientalismo moderno em suas críticas a esse sistema global buscando aparatos críticos na ecologia e culturas pós-modernas.

Se faz em caráter de urgência por parte da ecocrítica entender o processo da globalização na busca de criticar e desconstruir paradigmas existentes. De acordo com Garrad (2006) estes paradigmas estão principalmente na exploração dos países de terceiro mundo gerando consequências sociais e ambientais como a pobreza e degradação ambiental. Assim como para problemas literais, que não deixam de ser materiais, tendo os principais problemas ambientais passíveis de manipulação e que precisam de um reflexão mais cultural para desconstruir olhares equivocados.

Acreditamos que a compreensão desta constituição do global seja parte importante na compreensão de questões internas da ecocrítica. Entender o global que embora seja responsável pela expansão do capital, prejudicando os povos e a natureza é também um espaço de ampliação para entender as questões ambientais em escalas maiores. Dinamizar estas discussões e trazer ao centro as questões ambientais é fundamental tanto na expansão, como nas possíveis soluções que requerem ações de caráter jurídico.

Através das teorias do imaginário traçando um olhar pela cultura será possível entender o que Garrard (2006) denomina como globalização da imaginação que é o novo olhar através das grandes tecnologias da informação e mídias para a terra. Sendo uma das mais marcantes, a expedição Apollo à lua que tirou fotografias do planeta terra no espaço mostrando sua forma e mudando a compreensão imagética do planeta.

É com isto que este trabalho vem apontar uma imaginação ambiental global a partir da qual estamos todos conectados. Na era das tecnologias da informação as imagens virtuais se tornaram uma constante na vida do homem contemporâneo, principalmente com a dinamização dos problemas ambientais globais. Se dinamizou de tal forma que nessa constituição de imaginário global, desenvolveu-se também uma consciência ecológica mais ampla.

Embora a consciência ecológica e a preocupação com o meio ambiente já se mostrassem presentes na filosofia, cultura e política, foi o crescimento e avanço das

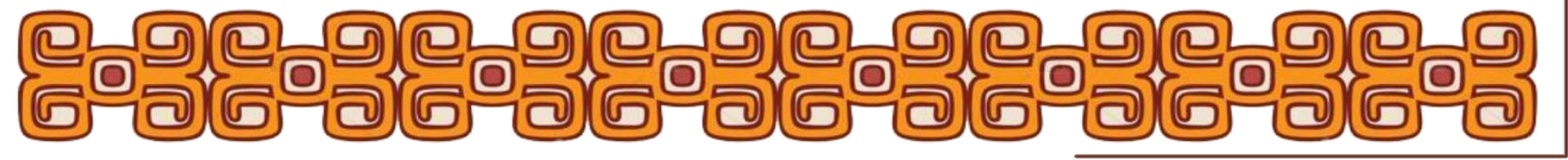




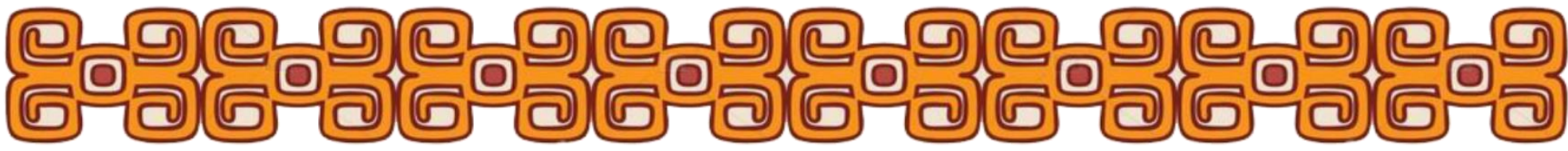

contaminação moral ou atos de impureza da alma como a masturbação. Essa definição muda na modernidade com Francis Bacon no texto "Da proficiência e do progresso do saber divino e humano" onde muda o sentido de moral e subjetivo para um fenômeno material e externo: "O sol [...] passa pelas poluições e mantém a si mesmo puro como antes".

Essa nova definição para a poluição traz uma mudança crucial pois influenciou diferentes culturas e formas de pensar, estando presente até hoje no inconsciente social que descreve Maffesoli. Afinal não é preciso ter qualquer tipo de formação ou nível intelectual para entender o sentido de poluição, tornando-se um conceito popular, mas que nas características próprias do lugar ganham novas formas e tipos de representação.

É para esta questão que a análise ecocrítica deve se preocupar e buscar relacionar através de algumas perguntas: como relacionar problemas ambientais de questão local com o global? Como discutir esses problemas de maneira mais ampla? Que contribuições a ecocrítica pode dar para possíveis soluções?

Tanto Terry Gifford (2009), quanto Michael P. Cohen (2004) falam da importância de se focalizar no lugar e região pela dialética local-global entendendo o senso de lugar em termos multiescalares que transcendem o lugar. Assim como também incluir uma crítica a paradigmas globais, científicos e culturais com o objetivo de entender a natureza como ela realmente é e não como é construída midiaticamente.

É nesse olhar atento com o lugar com elementos globais como ambientes, rios, florestas, pobreza, impactos do capital, poluição do meio ambiente que vamos perceber o pensamento global que através do particular será possível relacionar o local com o global. Trazendo esses problemas em uma amplitude maior que transcenda o local, buscaremos a discussão mais ampla desses elementos que estão em destaque na contemporaneidade. Bachelard (1974, pg. 183) vem falar da imagem nessa perspectiva quando explica que "A imagem poética não está submetida a um impulso. Não é o eco de um passado. É antes o inverso: pela explosão de uma imagem, o passado longínquo ressoa em ecos e não se vê mais em que profundidade

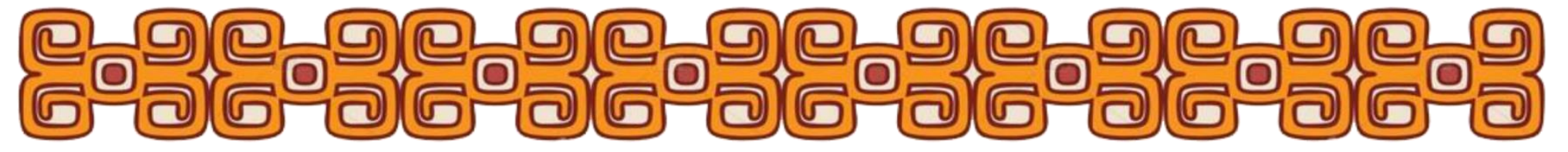




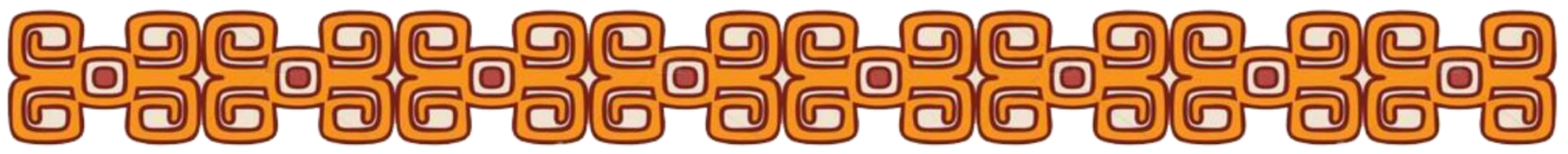

esses ecos vão repercutir e cessar." O passado cultural não importa mais, pois as questões ambientais estão na contemporaneidade e deve-se buscar o diálogo com a crise ecológica existente.

Dessa forma será possível uma reflexão mais ampla a partir da cultura para as questões ambientais ampliando as discussões a partir do local e discutir mais de perto estas questões entendo a localidade a partir da construção desse imaginário. É papel da ecocrítica estudar a relação do homem com o seu espaço e como esta relação se dá na cultura voltada para as preocupações centradas na Terra.

No caso desta análise, esta relação está na literatura enquanto representação imagética da realidade. As teorias em torno da literatura sempre se preocuparam com a relação do homem com o seu espaço e como esse espaço é retratado na literatura. Entender como esta dialética da produção literária se dá no regional e como estas representações tem uma conexão com o global, onde está a consciência ecológica, podendo encarar as ameaças locais em um diálogo maior.

Uma das principais críticas que a ecocrítica deve se atentar é como a natureza é construída e como ela realmente é. Durante a análise dos poemas de Thiago de Mello buscaremos esboçar esse imaginário local e o tratamento mais íntimo e próximo que o poeta dá as problemáticas locais dentro de sua poesia. No seu imaginário local mostra a natureza na Amazônia que vem ser o seu lugar, o seu espaço que no imaginário global ainda se tem uma ideia diferente de Amazônia.

Em seu lugar, no seu local nos seus múltiplos elementos que se verifica elementos que estão inteiramente ligados a uma problemática mais ampla e aberta que pode ser compreendida através do global. Através da sua realidade experiênciada que Thiago de Mello faz essa transfiguração através do seu imaginário para a ficção. Porém, a ecocrítica não vai se preocupar somente com essas representações, mas sim as representações que tragam preocupações com meio ambiente e analisar como se dá este processo na relação do humano com o não-humano na literatura.

Mas a principal mudança está justamente no despertar desses escritores para com a natureza assumindo uma postura crítica em suas produções. Kate Rigby (2000) em seu artigo intitulado "Ecocriticism" explica que a ecocrítica vem lembrar da terra

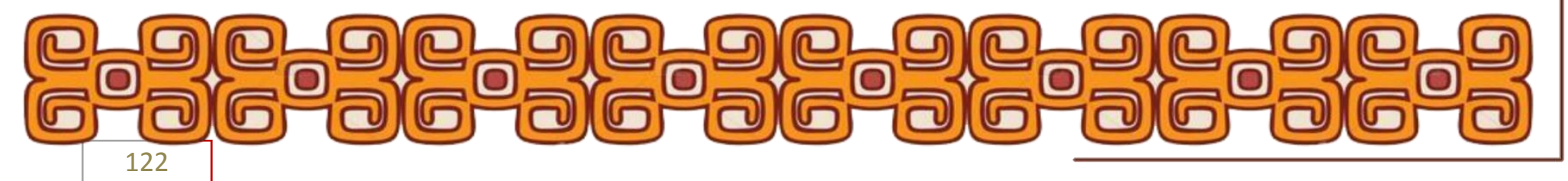




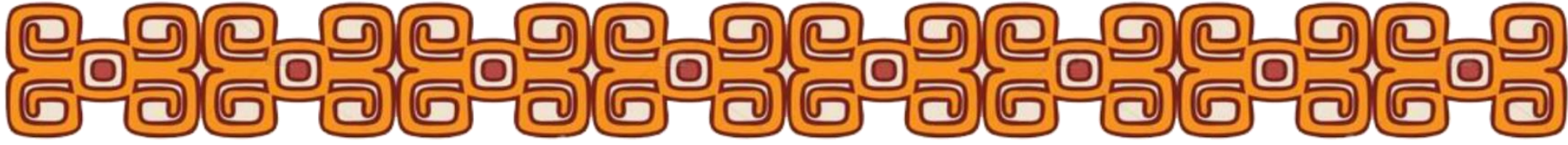

Este fato se exerce em sua poesia por aquilo que Goodbody (2014) chama de estruturas opressivas do sistema cultural, dando voz a aquilo que é suprimido por essas culturas gerando um grande impacto cultural. Sua poesia se torna uma verdadeira voz para os pobres e oprimidos na Amazônia continental e abraça as causas ambientais gerando um forte diálogo com as principais discussões ambientalistas da contemporaneidade.

Compreender a relação de Thiago de Mello enquanto homem com o seu espaço é parte fundamental da ecocrítica neste trabalho, pois é através desta compreensão que estamos dialogando entre literatura e ambiente. Em sua lírica, posiciona a natureza como ponto central de seus interesses evidenciando o cuidado que se deve ter com a fauna, flora, os rios retirando aprendizados que estão na vivência e no dia-a-dia do homem amazônico que são elementos catalizadores do global, pois essa relação existe em outras partes do mundo, mas que na região ganham novas formas.

O homem amazônico vive em uma sábia união com as águas, a floresta e os animais como em uma convivência solidária que é regida por leis e valores únicos deste lugar:

"Eu venho desse reino generoso, onde os homens que nascem dos seus verdes continuam cativos, esquecidos, e contudo profundamente irmãos das coisas poderosas, permanentes como as águas, o vento e a esperança." (MELLO, 2002, p. 28)

O poeta demonstrar neste poema a relação do amazônida com o seu espaço em uma relação de integração com a natureza, cujos princípios e valores condicionam a sua maneira de viver. O homem amazônico usa a floresta, não a devasta, sendo um povo que mesmo esquecido por grande parte das regiões metropolitanas permanece em serenidade com a natureza em suas coisas mais ínfimas e simples. Mas este equilíbrio tem estado em constante ameaça.

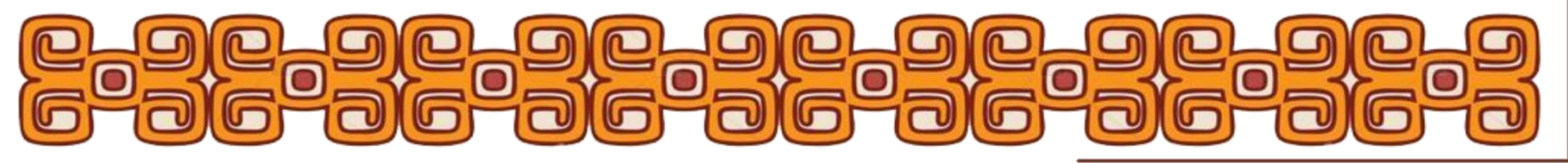




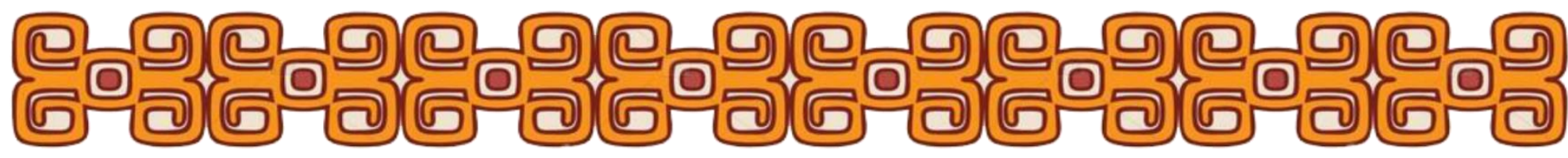

Interpretar as manifestações culturais através da dialética local-global é o primeiro passo para entender como as consequências do capital global tem afetado diferentes culturas.

Os ecocríticos enquanto investigadores devem observar estas representações com um olhar mais próximo e intimo que só a poesia pode mostrar e entender o lugar como mediador/catalizador de elementos globais. Dessa forma perceber com mais clareza que o discurso ambiental e a consciência ecológica vem aparecendo com mais frequências nas produções artísticas de modo geral.

Dentro do imaginário literário foi possível perceber a formação dessas representações que como explica Durand (2011, pg. 10) "A imagem pode se desenvolver dentro de uma descrição infinita e uma contemplação inesgotável...". Estando sujeita a diferentes interpretações e a perspectiva do pensamento ecocrítico na poesia de Thiago de Mello lança um novo olhar a partir dos elementos que usa como matéria poética, onde constrói o seu espaço dentro de sua lírica.

A valorização do homem Amazônico colocando seu modo de habitar como um modelo ecológico de sustentabilidade com as plantas, os animais, as águas e tudo que compõe o espaço geográfico mostra sua postura ética ambiental. As preocupações com esse ecossistema transforma sua poesia em um verdadeiro manifesto verde. $\mathrm{E}$ esta análise buscou através desse lugar compreender estas problemáticas no contexto global da Amazônia.

Cohen (2004) afirma que a função mais importante da literatura hoje é redirecionar a consciência humana sobre o seu lugar em um mundo ameaçado, e o poeta, em seu imaginário literário, demostra as ameaças que a Pátria da Água enfrenta. Em síntese, este trabalho cumpre seus objetivos de compreender 0 imaginário global dentro da poesia de Thiago de Mello trazendo uma reflexão cultural sobre a Amazônia. Assim como contribuições para os estudos recentes da ecocrítica em torno da globalização. O imaginário global se faz presente no seu espaço poético e através dos elementos deste espaço foi possível trazer uma reflexão sobre a Amazônia globalmente.

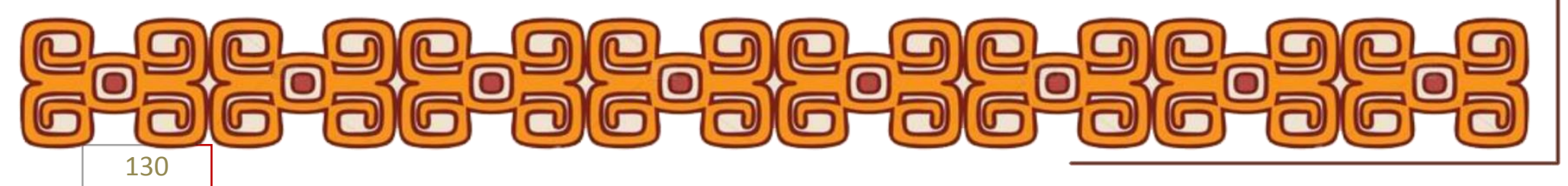




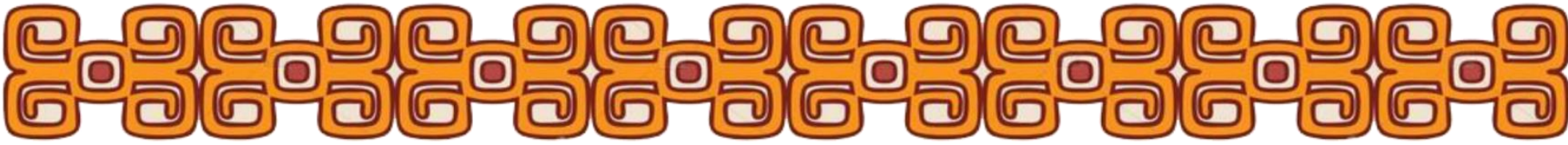

\section{REFERÊNCIAS BIBLIOGRÁFICAS}

AB'SÁBER, Aziz. A Amazônia: Do discurso à Práxis. 2. Ed. - São Paulo: Editora da Universidade de São Paul, 2004.

AB'SÁBER, Aziz. Problemas da Amazônia brasileira. Entrevista a Dario Luis Borellli et al. Estud. av. vol.19 no.53 São Paulo Jan./Apr. 2005.

BACHELARD, G. A Poética do Espaço. Trad. Franklin Leopoldo e Silva. São Paulo: Abril, Curitiba, 1974

CARNEIRO, Augusto Cunha. A história do Ambientalismo. - Porto Alegre: Editora Sagra Luz-zatto, 2003.

COHEN, Michael P. Blues in the Green: Ecocriticism Under Critique. Environmental History. 2004. Posted with permission to the ASLE https://website.www.asle.org.

DURAND, Gilbert. O imaginário: ensaio acerca das ciências e da filosofia da imaginação/ Gilbert Durand; tradução Renée Eve Levié. - $5^{a}$ ed. - Rio de Janeiro: DIFEL, 2011.

GUATTARI, Féliz. As três ecologias; tradução Maria Cistina F. Bittencourt. Campinas, SP: Papirus, 1990.

GARRARD, Greg. Ecocrítica; tradução de Vera Ribeiro. Brasília: Editora Universidade de Brasília, 2006.

GIFFORD, Terry. A Ecocrítica na Mira da Crítica Atual. Rio de Janeiro: Terceira Margem, 2009. Número 20.

GOODBODY, A. A Ecocrítica alemã: Um panorama. Pandaemonium, São Paulo, v. 17, n. 24, Dez. /2014, p. 1-19.

GONZÁLEZ, Maurício Ostria. Aproximación Ecocrítica a Textos Literários. Quito: Kipus Revista Andina de Letras, 2010, n. 27. ISSN:1390-0102

JOHNSON, Loretta. Greening the Library: The Fundamentals and Future of Ecocriticism. CHOICE: Bibliographic Essay, 2009. Posted with permission to the ASLE https://website.www.asle.org.

MELLO, Thiago de. Melhores poemas Thiago de Mello. 1. Ed. São Paulo: Global, 2009 - (Coleção Melhores poemas)

MELLO, Thiago. Amazonas, pátria da água, e; Notícia da visitação que no verão de 1953 ao Rio Amazonas e seus barrancos. Rio de Janeiro: Bertrand Brasil, 2002.

MELLO, Thiago de. Amazonas: pátria da água = Amazonas: water hertland/ textos e poemas/ texts and poems Thiago de Mello; fotografias/ photographs Luiz Cláudio Marigo; São Paulo: Gaia: Editora Boccato, 2007.

PIZARRO, Ana. Amazônia: as vozes do rio: imaginário e modernização; tradução Rômulo Monte Alto. - Belo Horizonte: Editora UFMG, 2012.

RIGBY, Kate. Ecocriticism. Literary and Cultural Criticism at the Twenty-First Century, Edinburgh: Edinburgh UP, 151-78. Digitised for ASLE with kind permission of the publishers.

SILVA, Juremir Machado da. Tecnologias do imaginário: esboços para um conceito. COMPÓS TRINDADE, Liana Sálvia. O que é imaginário / liana Trindade, François Laplantine. São Paulo; Brasiliense, 1997.

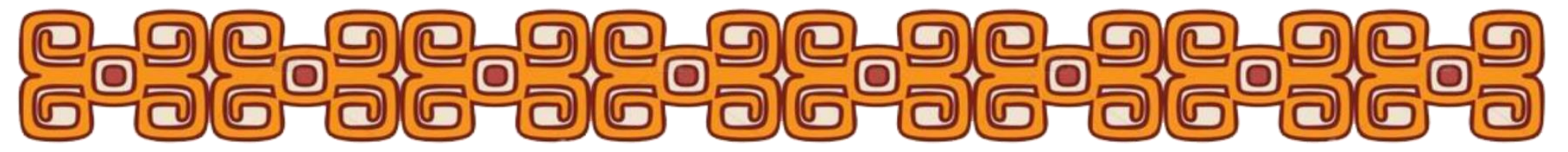

